\author{
S. Ivanovski ${ }^{1 *}, C$. Vaquette ${ }^{2}$, \\ S. Gronthos ${ }^{3}$, D.W. Hutmacher ${ }^{2}$, \\ and P.M. Bartold ${ }^{4}$
}

${ }^{1}$ Griffith Health Institute, Regenerative Medicine Center, School of Dentistry and Oral Health, Griffith University, Gold Coast, Australia; ${ }^{2}$ Institute of Health and Biomedical Innovation, Kelvin Grove, Brisbane, Australia; ${ }^{3}$ Mesenchymal Stem Cell Laboratory, School of Medical Sciences, University of Adelaide, Adelaide, Australia; and ${ }^{4}$ Colgate Australian Clinical Dental Research Centre, Department of Dentistry, University of Adelaide, Adelaide, Australia; *corresponding author, s.ivanovski@griffith.edu.au

J Dent Res 93(12):1212-1221, 2014

\section{Multiphasic Scaffolds for Periodontal Tissue Engineering}

$\mathbf{T}$ he ultimate goal of periodontal therapy is the regeneration of the original architecture and function of the periodontal complex, which involves the formation of new cementum on the tooth root, along with new periodontal attachment between newly formed bone and cementum. This outcome is not predictably achieved with conventional therapy (Caton et al., 1980), largely due to the complex structure of the periodontium, consisting of both soft (gingiva, periodontal ligament) and hard (bone, cementum) tissues that compete during the regenerative process.

Several techniques and products aimed at achieving periodontal regeneration are currently available for clinical use. Guided tissue regeneration (GTR) is the best documented regenerative technique that utilizes a barrier membrane to promote the selective repopulation of the periodontal defect by cells derived from the remaining periodontal ligament (Karring et al., 1993). Although histologically verified regeneration can be achieved in selected cases (Gottlow et al., 1986), the clinical outcomes are generally unpredictable (Needleman et al., 2006). Attempts have also been made to utilize bioactive molecules to promote periodontal regeneration, including enamel matrix derivative and growth factors such as platelet-derived growth factor (Esposito et al., 2009; Darby and Morris, 2013). Results have been similar to those obtained with GTR, with these approaches suitable for use in only a limited range of clinical scenarios (infrabony defects, mandibular molar class II furcations), with complete regeneration remaining elusive in the majority of cases.

A tissue-engineering approach is an inherently sound strategy for regenerating the hierarchical structures of the periodontium, whereby periodontal tissues would be constructed in the laboratory under controlled conditions and then surgically implanted (Bartold et al., 2000). Given the complexity of the periodontal tissue architecture and the need for a precisely coordinated wound healing response, the use of advanced scaffold designs that are able to guide the spatiotemporal requirements for periodontal regeneration has the potential to significantly improve therapeutic outcomes. The use of such scaffolds could be complementary to current clinical procedures such as GTR and the use of bioactive molecules, and have the ability to be combined with cellbased approaches.

\section{MULTIPHASIC SCAFFOLDS IN REGENERATIVE MEDICINE}

A multiphasic scaffold can be defined by the variation within the architecture (porosity, pore organization, etc.) and the chemical composition of the resulting construct, which usually recapitulates to some extent the structural 
organization or the cellular and biochemical composition of the native tissue. Multiphasic scaffolds aimed at imparting biomimetic functionality to tissue-engineered bone and soft tissue grafts have been recognized for some time as having significant potential to enable clinical translation in the field of orthopaedic tissue engineering and have more recently emerged in the field of periodontal tissue regeneration.

Orthopaedic reconstruction, like periodontal regeneration, often requires the management of soft to hard tissue interfaces, such as ligament to bone, tendon to bone, and cartilage to bone (Lu et al., 2010). Furthermore, as is the case in periodontal regeneration, a significant clinical challenge is the inability to achieve functional integration of different soft and hard tissue components, such as bone, ligaments, cartilage, or tendons, with one another or with the host environment. In these situations, it has been proposed that successful tissue integration in vivo could be facilitated through the use of advanced scaffold design to facilitate regeneration of the original soft/hard tissue architecture. In particular, strategic biomimicry could be imparted through the use of multiphasic scaffolds to reestablish the critical structure-function relationship inherent to the native soft tissue-bone interface. A key consideration is the preengineering of distinct yet continuous tissue regions combined with a gradient of mechanical properties (Dormer et al., 2010).

Osteochondral regeneration is at the forefront of the development of multilayered structures, owing to the inherent complexity of the native tissue and to the necessity for reestablishment of the physiologic loading and function of the joint. These constructs are usually designed with biomechanical mimicry; hence, a stiff porous scaffold-suitable for withstanding the physiologic loading of the joint - is generally utilized for regenerating the subchondral bone. A great variety of materials are available for developing an appropriate bone compartment. Commonly utilized solutions include biodegradable polymeric scaffolds that may be combined with osteoconductive bioceramic particles and natural biopolymers (Frenkel et al., 2005; Ho et al., 2010; Wang et al., 2010), rapid prototyped porous polymeric or metal structures (Mrosek et al., 2010), bioceramics that can also be combined with a polymeric matrix for enhanced flexibility (Scotti et al., 2007), and porous cross-linked collagen scaffolds (Kon et al., 2010). The cartilage compartment is generally composed of a soft material, such as a hydrogel (alginate, chitosan, collagen type I and II), although synthetic polymers have also been reported (Harley et al., 2010; Kon et al., 2010; Chen et al., 2011; Jeon et al., 2014).

A key aspect of multiphasic scaffold fabrication is to achieve strong cohesion among the different phases to ensure that surgical handling and physiologic loading will not damage the construct (Vaquette and Cooper-White, 2013). This is generally not trivial, and a higher degree of complexity is reached when cellularized compartments are utilized. Indeed, the necessity for preserving cell viability and ensuring sterility significantly reduces the range of suitable solutions for compartment assembly. Fibrin glue is the most commonly used vehicle for cell delivery, although a partially de-cross-linked hydrogel has been utilized (Jeon et al., 2014).

In the context of periodontal regeneration, the tissue compartmentalization properties that can be imparted by multiphasic scaffolds are particularly desirable, as they have the potential to optimize the spatiotemporal delivery of the key components necessary for new periodontal attachment formation (incorporating bone, periodontal ligament, and cementum).

\section{TISSUE-ENGINEERING APPROACHES TO PERIODONTAL REGENERATION}

It has long been recognized that conventional surgical and nonsurgical periodontal treatment does not reconstitute the original function and structure of the periodontium (Caton et al., 1980). This has led to the development of dedicated surgical techniques aimed at reliably and predictably achieving periodontal regeneration. The most commonly utilized approach is the principle of GTR, which utilizes barrier membranes to promote the selective repopulation of the periodontal defect by cells capable of re-creating periodontal attachment formation (i.e., alveolar bone, periodontal ligament) at the expense of those that do not (gingival epithelium and connective tissue; Karring et al., 1993). For the first time, GTR addressed the need to understand and manipulate the complex periodontal wound-healing process, as well as enhance wound stability and maintain the space necessary for new bone and periodontal attachment to occur. The application of bioactive molecules and growth factors - such as enamel matrix derivative, basic fibroblast growth factor (bFGF, FGF-2), and plateletderived growth factor-has also been utilized (Esposito et al., 2009; Murakami, 2011; Darby and Morris, 2013). However, although approaches based on the use of barrier membranes (GTR) and growth factors have been shown to promote some regeneration in a select type of periodontal defects, the clinical outcomes have been unpredictable, and complete regeneration remains elusive (Ivanovski 2009). A major limitation remains the inability to exert spatiotemporal control over the wound-healing process. To this end, tissue-engineering approaches have been recognized for some time as having the ability to address these limitations (Bartold et al., 2000).

The fundamental concept underlying tissue engineering is to combine a scaffold with living cells or biologically active molecules to form a "tissue-engineering construct" that, in the presence of adequate blood supply, promotes the repair or regeneration of tissues (Bartold et al., 2000; Bartold et al., 2006). Thus far, most periodontal tissue-engineering approaches have focused on the potential of progenitor (stem) cells to promote new periodontal attachment. Periodontal ligament stem cells, as well as other mesenchymal stem cells, have been used with promising results (Hynes et al., 2012). The general approach has been to combine these cells with a carrier and insert them into periodontal defects. The drawback of this approach is the inability to deliver the cells to specific locations within the periodontium; hence, it does not fully address the requirements for the successful regeneration of this complex structure. In this context, the use of cell sheets has the potential to facilitate more controlled and targeted cell delivery within the periodontal defect (Ishikawa et al., 2009).

Cell sheet engineering is a recent technology that utilizes a temperature-responsive cell culture dish, which responds reversibly to temperature changes (Hirose et al., 2000). The rationale for this approach is that this nonenzymatic harvesting of cells is 
Table 1. Design Features of Studies Utilizing Multiphasic Scaffolds for Periodontal Tissue Engineering

\begin{tabular}{|c|c|c|}
\hline \multicolumn{3}{|c|}{ Bilayered occlusive membrane + bone compartment } \\
\hline Membrane & Bone compartment & \\
\hline $\begin{array}{l}75 / 25 \text { polylactide-co-glycolide (PLGA) and calcium } \\
\text { phosphate particles fabricated by casting the mixture } \\
\text { onto a mold. }\end{array}$ & $\begin{array}{l}75 / 25 \text { PLGA and calcium phosphate particles fabricated by } \\
\text { solvent casting particulate (sugar) leaching. The porous structure } \\
\text { was further coated with biomimetic calcium phosphate. }\end{array}$ & $\begin{array}{l}\text { Carlo-Reis et al. } \\
\text { (2011) }\end{array}$ \\
\hline $\begin{array}{l}\text { Blend of starch and polycaprolactone (PCL; 30/70 wt\%) } \\
\text { obtained by solvent casting. }\end{array}$ & $\begin{array}{l}\text { Consists of a porous fibrous scaffold made of a starch and poly } \\
\text { (E-caprolactone) blend ( } 30 / 70 \mathrm{wt} \%) \text {. The scaffold is manufactured } \\
\text { by wet spinning and further functionalized by calcium saline to } \\
\text { enhance the osteoconductive property of the construct. } \\
\text { alized biphasic scaffolds }\end{array}$ & $\begin{array}{l}\text { Requicha et al. } \\
\quad(2014)\end{array}$ \\
\hline Bone compartment & Periodontal ligament compartment & \\
\hline $\begin{array}{l}\text { PLGA solution cast into a 3-dimensional printed wax } \\
\text { mold, which is thereafter dissolved, hence creating } \\
\text { a porous PLGA structure. Primary human gingival } \\
\text { fibroblasts transduced with BMP-7 are seeded with } \\
\text { bovine plasma fibrinogen. }\end{array}$ & $\begin{array}{l}\text { A PCL solution cast into a 3-dimensional printed wax mold. The } \\
\text { wax mold is thereafter dissolved, hence creating a porous } \mathrm{PCL} \\
\text { structure. The periodontal compartment is seeded with human } \\
\text { periodontal ligament cells. }\end{array}$ & $\begin{array}{l}\text { Park et al. } \\
\text { (2010) }\end{array}$ \\
\hline $\begin{array}{l}\text { A fused deposition modeling PCL scaffold is utilized } \\
\text { for the bone compartment. The macroporous } \\
\text { architecture enables blood clot stabilization and } \\
\text { neovascularization. }\end{array}$ & $\begin{array}{l}\text { A PCL solution electrospun membrane is utilized to support and } \\
\text { deliver a 3-layer fibroblast periodontal cell sheet. The membrane } \\
\text { is partially occlusive owing to its microporosity, hence rendering } \\
\text { the biphasic construct highly compartmentalized. }\end{array}$ & $\begin{array}{l}\text { Vaquette et al. } \\
\quad(2012)\end{array}$ \\
\hline $\begin{array}{l}\text { A fused deposition modeling PCL scaffold is utilized } \\
\text { for the bone compartment and further coated with } \\
\text { a layer of calcium phosphate for enhancing the } \\
\text { osteoconductive properties of the construct. }\end{array}$ & $\begin{array}{l}\text { Three-layered fibroblast periodontal cell sheets are delivered } \\
\text { through the utilization of a melt electrospun membrane with } \\
\text { macroscopic pore size and a concentrically organized ring } \\
\text { pattern. }\end{array}$ & $\begin{array}{l}\text { Costa et al. } \\
\text { (2014) }\end{array}$ \\
\hline $\begin{array}{l}\text { Compartmen } \\
\text { Fused deposition modeling is utilized for manufacturing a } \\
(90 / 10) \text {. While the } 3 \text { phases have similar chemical cor } \\
\text { attempt to favor the differentiation of the cells into relev } \\
\text { and } 300 \mu \mathrm{m} \text { for cementum, periodontal ligament, and } \\
\text { compartmentalize the construct. To further affect cell dif } \\
\text { as amelogenin, connective tissue growth factor and BM } \\
\text { stem cells are seeded into the multiphase construct with }\end{array}$ & $\begin{array}{l}\text { talized triphasic scaffold } \\
\text { triphasic scaffold made of a mixture of PCL/hydroxyapatite } \\
\text { mpositions, the architecture of each compartment is modified in an } \\
\text { ant phenotypes. Microchannels of different diameters (100, } 600 \text {, } \\
\text { bone compartment, respectively) are created to architecturally } \\
\text { ferentiation, PLGA microspheres loaded with biological cues, such } \\
\text { P-2 are inserted in the relevant tissue compartment. Dental pulp } \\
\text { collagen type } 1 \text { gel. }\end{array}$ & Lee et al. $(2014)$ \\
\hline
\end{tabular}

noninvasive, gentle, and harmless to cells while maintaining an intact extracellular matrix (Kushida et al., 1999). Periodontal ligament cells (PDLs) cultured via this cell sheet technique have shown promising regenerative potential after transplantation in a variety of animal models (Akizuki et al., 2005; Hasegawa et al., 2005; Gomez Flores et al., 2008; Iwata et al., 2009). One of the major issues associated with the use of cell sheets is the difficulty in achieving biomechanical fixation (Iwata et al., 2009). In this context, the concurrent use of a multiphasic scaffold not only would provide support for the periodontal cell sheet but could also create the space necessary for bone formation within the periodontal defect.

\section{MULTIPHASIC SCAFFOLDS: GENERAL PRINCIPLES}

Multiphasic scaffolds are expected to perform various functions, including the support of cell colonization, migration, growth, and differentiation. A critical consideration is the requirement to facilitate timely revascularization of the tissue-engineered construct following implantation in vivo. The design of these scaffolds also needs to consider physicochemical properties, morphology, and degradation kinetics.

External size and shape of the construct are of importance, particularly if the construct is customized for an individual patient. Most important, clinically successful constructs should stimulate and support both the onset and the continuance of tissue ingrowth, as well as subsequent remodeling and maturation by providing optimal stiffness and external and internal geometrical shapes. These constructs need to be fabricated to precisely replicate the anatomy/form of the defect area to allow cell delivery and neovascularization while maintaining space for subsequent tissue regeneration. Continuous cell and tissue remodeling is important for achieving stable biomechanical conditions and vascularization at the host site. In addition to these essentials of mechanics and geometry, a suitable construct should (1) possess a 3-dimensional and highly porous interconnected pore network with surface properties that are optimized for cell attachment, migration, proliferation, and differentiation and that enable flow transport of nutrients and metabolic waste and (2) be biocompatible and biodegradable with a controllable 
Table 2. Regenerative Outcomes Reported in Studies Utilizing Multiphasic Scaffolds for Periodontal Tissue Engineering

\begin{tabular}{|c|c|c|}
\hline In Vivo Model & Outcomes & \\
\hline \multicolumn{3}{|c|}{ Bilayered occlusive membrane + bone compartment } \\
\hline Dog: class II furcation defects & $\begin{array}{l}\text { New cementum, bone, and periodontal ligament with Sharpey's fiber insertion was } \\
\text { observed except in the most coronal parts of the defects. }\end{array}$ & $\begin{array}{l}\text { Carlo-Reis et al. } \\
\text { (2011) }\end{array}$ \\
\hline \multicolumn{3}{|c|}{ Compartmentalized biphasic scaffolds } \\
\hline $\begin{array}{l}\text { Immunodeficient mice: ectopic } \\
\text { (subcutaneous on a dentine } \\
\text { slice) }\end{array}$ & $\begin{array}{l}\text { The best ectopic regeneration is obtained in the BMP-7-transduced gingival cell-seeded } \\
\text { construct, with higher bone formation, deposition of cementum-like tissue, and } \\
\text { insertion of fibers. }\end{array}$ & $\begin{array}{l}\text { Park et al. } \\
\text { (2010) }\end{array}$ \\
\hline $\begin{array}{l}\text { Immunodeficient rat: surgically } \\
\text { created periodontal defect }\end{array}$ & $\begin{array}{l}\text { Enhanced periodontal-like tissue orientation was demonstrated in the case of the fiber } \\
\text { guiding compared to random-orientation scaffold. }\end{array}$ & $\begin{array}{l}\text { Park et al. } \\
\text { (2012) }\end{array}$ \\
\hline $\begin{array}{l}\text { Athymic rats: ectopic } \\
\text { (subcutaneous on a dentine } \\
\text { slice) }\end{array}$ & $\begin{array}{l}\text { Higher rate of cementum-like tissue deposition at the dentin-cell sheets interface was } \\
\text { observed. However, there was poor integration of the new ligament-like tissue with } \\
\text { the bone compartment. }\end{array}$ & $\begin{array}{l}\text { Vaquette et al. } \\
\text { (2012) }\end{array}$ \\
\hline $\begin{array}{l}\text { Athymic rats: ectopic } \\
\text { (subcutaneous on a dentine } \\
\text { slice) }\end{array}$ & $\begin{array}{l}\text { The frequency of cell sheet attachment is increased in the presence of cell sheets, } \\
\text { and the integration of the new periodontal ligament in the newly formed bone is } \\
\text { enhanced. Periodontal fiber orientation is achieved though the specific pattern of the } \\
\text { melt electrospun membrane. }\end{array}$ & $\begin{array}{l}\text { Costa et al. } \\
\text { (2014) }\end{array}$ \\
\hline \multicolumn{3}{|c|}{ Compartmentalized biphasic scaffolds/triphasic scaffold } \\
\hline $\begin{array}{l}\text { Immunodeficient mice: ectopic } \\
\text { (subcutaneous) }\end{array}$ & $\begin{array}{l}\text { The delivery of biological cues combined with the seeding of DPSCs leads to the } \\
\text { formation of bone, PDL and cementum/dentin-like tissue in the various compartments, } \\
\text { and inserting periodontal fiber orientation was observed. }\end{array}$ & Lee et al. (2014) \\
\hline
\end{tabular}

rate to complement cell/tissue growth and maturation (Hutmacher and Cool, 2007).

It is essential to understand and control this scaffold degradation process. In the early days of tissue engineering, it was thought that scaffolds should degrade and resorb as the tissue is growing. However, it is important to note that tissue ingrowth and maturation differ temporally from tissue to tissue. Furthermore, tissue ingrowth does not equate to tissue maturation and remodeling, and a defect filled with immature tissue should not be considered "regenerated." Hence, many scaffold-based strategies have failed in the past, as the scaffold degradation was more rapid than tissue remodeling or maturation. It is important that the scaffold remains intact as the tissue matures in the scaffold pores, with bulk degradation occurring later (Lam et al., 2009).

\section{MULTIPHASIC SCAFFOLD REQUIREMENTS FOR PERIODONTAL TISSUE ENGINEERING}

Periodontal multitissue engineering with appropriate spatiotemporal coordination is challenging due to the complex interaction of multiple soft and hard tissues. The hierarchical structure of the periodontal tissues demands the development of methods for scaffold preparation that allow design of pore sizes spanning from micro- to macroscale, eventually with anisotropic pore distribution and a spatial control over structural geometry and composition. It is important to develop scaffolds that remain intact as newly formed tissue matures within the porous and fully interconnected multiphasic scaffold architecture, allowing the onset of degradation only after the regenerated tissue has remodeled.

Periodontal tissue-engineering strategies need to progress from a focus on tissue formation toward an emphasis on tissue function, including the restoration of physiologic loading and homeostasis. As such, multiphasic scaffolds need to place an emphasis on functional biomimicry, especially in terms of addressing the key interface between the periodontal ligament and the tooth root, whereby the formation of cementum with the insertion of functional periodontal ligament fibers is essential. Additional requirements are the provision of space for bone regeneration and the prevention of epithelial downgrowth along the root surface. Notably, multiphasic scaffolds can be combined with established periodontal regenerative approaches, such as GTR and bioactive molecules, as well as progenitor/ stem cell-based approaches, to optimize regenerative outcomes.

In summary, key considerations for multiphasic scaffolds for periodontal tissue engineering are (1) compartmentalized bone and periodontal attachment tissue formation that is integrated over time, (2) the promotion of cementum formation onto the root surface, and (3) the formation of appropriately oriented periodontal ligament fibers that insert into newly formed bone and cementum.

\section{MULTIPHASIC SCAFFOLDS AND PERIODONTAL TISSUE ENGINEERING}

Although the use of a multiphasic scaffold approach would seem to be ideally suited to periodontal tissue engineering, there has been a scarcity of work on advanced scaffold development to support this approach. Only recently, several groups have started investigating this field and have explored this approach. Table 1 summarizes the design features of the multiphasic constructs used in these studies, while Table 2 outlines the in vivo regenerative outcomes that were reported.

\section{Modified GBR Membrane with Bone Compartment}

A semirigid PLGA (polylactide-co-glycolide acid) + CaP (calcium phosphate) bilayered biomaterial construct has been 

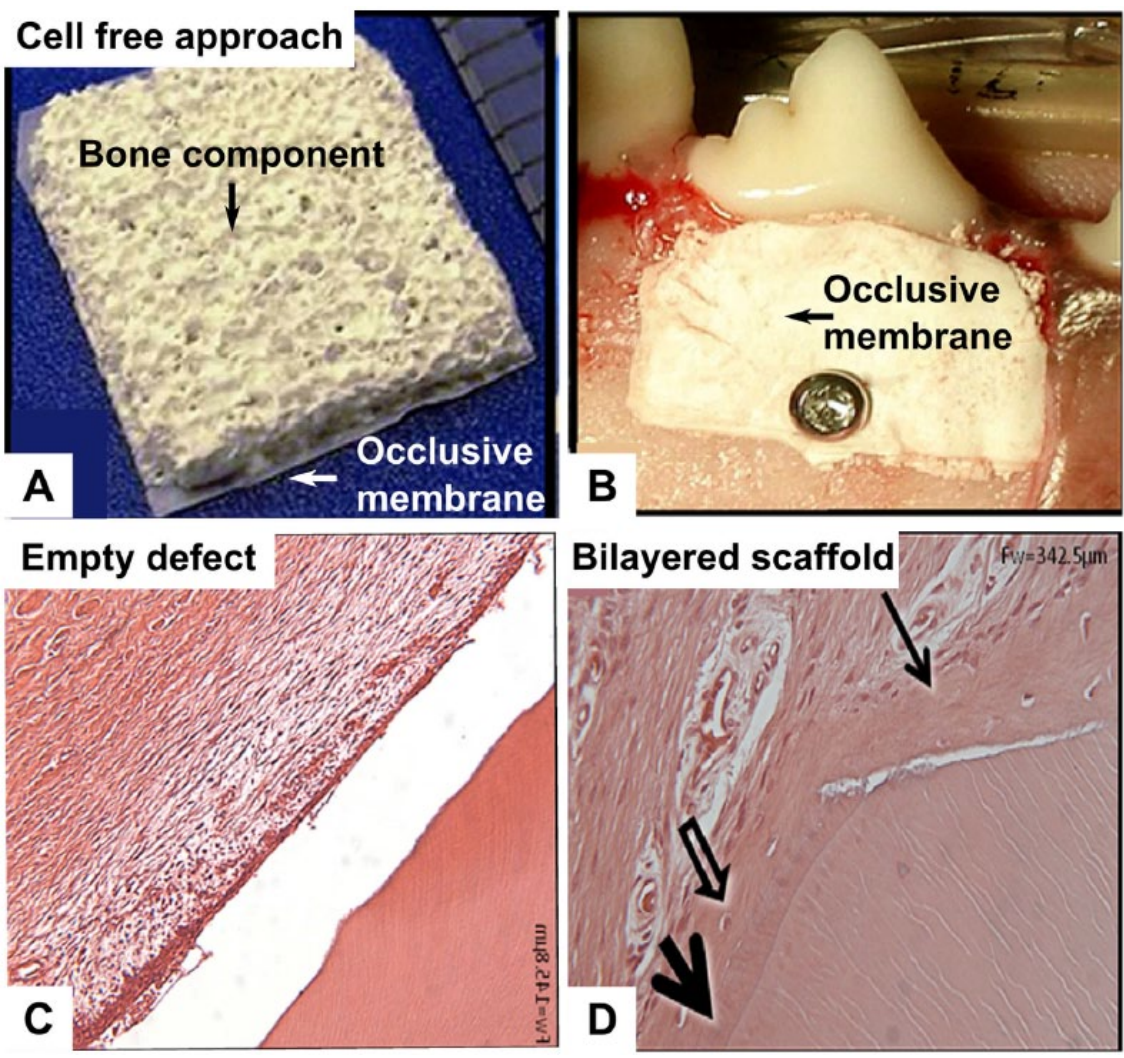

Figure 1. Bilayered macroporous composite scaffold composed of 75/25 PLGA (polylactideco-glycolide) and calcium phosphate utilized in modified guided tissue regeneration approach. (A) Gross morphology of the scaffold consisting of an occlusive membrane for preventing soft tissue infiltration and a porous scaffold for promoting bone formation. (B) Placement of the bilayered scaffold in a canine class II furcation defect. (C) Hematoxylin and eosin staining of the control (empty defect), showing no periodontal attachment on the root surface. (D) Hematoxylin and eosin staining of the experimental group, demonstrating appropriate regeneration with the formation of new cementum (arrows), bone, and functional insertion of periodontal fibers. Images from Carlo-Reis et al. (2011), reproduced with permission from publisher (Elsevier).

developed, which has a continuous outer barrier membrane obtained by solvent casting and an inner topographically complex and porous component fabricated by solvent casting/ sugar leaching, as shown in Figure 1A (Carlo-Reis et al., 2011). This approach relies on the osteoconductivity of the calcium phosphate material and the space maintenance properties of the porous PLGA structure to achieve periodontal regeneration. The study compared periodontal debridement alone with debridement and biomaterial implantation in the treatment of class II furcation defects in dogs, as displayed in Figure 1B. Clinical evaluation, micro-computed tomography, histology, and backscattered electron imaging were used for data analysis. Trabecular number and trabecular thickness were all significantly greater in the treated group, while trabecular separation was significantly greater in the control group. New cementum, bone, and perpendicular periodontal ligament fiber insertion was seen in only the treated group (Fig. 1C and D). The authors noted that the bilayered PLGA + CaP construct had the favorable properties of preventing tissue collapse into the defect and retaining the blood clot throughout the buccal defect.

This bilayered construct approach represents a modification of the traditional GTR technique, whereby the construct acts as both a barrier and an enhanced space maintainer. Despite these promising results, the authors noted that the periodontium was not well regenerated in the most coronal regions of the defect. They hypothesized that the space maintenance property of the bilayered construct decreased over time as the scaffold gradually degraded. Indeed, at 120 days postimplantation, no traces of the polymeric material were found. This study highlights the importance of appropriate material selection and demonstrates that a polymer undergoing slower in vivo degradation might be more suited for periodontal regeneration. Furthermore, the approach relied solely on the regenerative performance of the host progenitor cells residing in the vicinity of the damaged area. Combining these bilayered scaffolds with a cell-based approach, especially one that allows targeted delivery such as a cell sheet, may improve in vivo outcomes.

More recently, a similar "bilayered membrane" approach was reported that used a scaffold fabricated with a combination of starch and a slower-degrading polymer (polycaprolactone [PCL]; Requicha et al., 2014). Similar to the strategy used by Carlo-Reis et al. (2011), the outer phase of the bilayered construct was designed as an occlusive membrane for preventing the surrounding soft tissue from invading the periodontal defect, while the inner phase was manufactured by wet spinning, thus creating a highly porous structure with macroscopic pore size suitable for bone regeneration. Although this bilayered scaffold was not utilized in an in vivo model, the in vitro evaluation demonstrated that the bone compartment supported cell proliferation, and bone formation-related genes were upregulated when the scaffold was functionalized with silanol groups.

\section{Compartmentalized Biphasic Scaffolds with Fiber-Guiding Properties}

Another multiphasic approach utilized PCL-polyglycolic acid constructs for controlling fiber orientation and facilitating morphogenesis of the periodontal tissue complex (Park et al., 2010; Park et al., 2012; Fig. 2). This approach utilized a multicompartmental scaffold architecture using computational scaffold design and manufacturing by 3-dimensional wax printing. In these studies, the scaffolds were seeded with cells transduced with recombinant adenovirus-encoding murine bone morphogenetic protein 7 (AdBMP-7). In the first study, newly formed tissues demonstrated the interfacial generation of parallel and obliquely oriented fibers that formed human tooth dentin-ligament-bone complexes in an in vivo ectopic periodontal regeneration model 


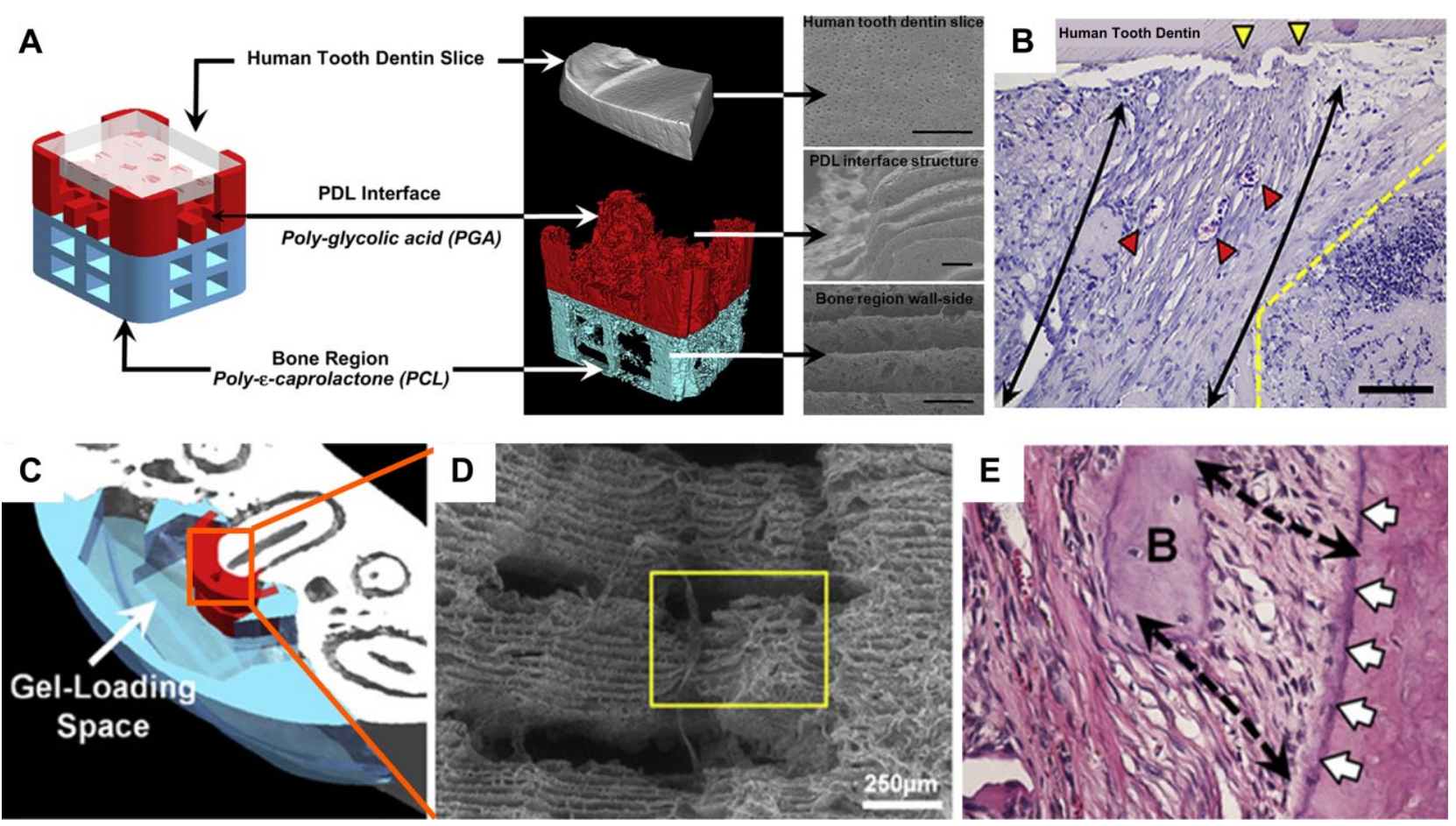

Figure 2. Compartmentalized biphasic scaffolds manufactured using a 3-dimensional wax printing method. After removal of the sacrificial wax, polymer solutions are cast in the resulting molds. Porous structures are then obtained by dissolving the wax used to create the mold. (A) Biphasic scaffold made of polyglycolic acid (white) and polycaprolactone (red) for the bone and periodontal compartments, respectively. (B) The performance of cell-seeded biphasic scaffold is assessed in an ectopic periodontal regeneration model in mice that demonstrates some level of regeneration with functional orientation of the newly formed periodontal fibers (scale bar, $50 \mu \mathrm{m}$ ). (C) Customized polycaprolactone biphasic scaffold manufactured with the same methodology. (D) This approach enabled the creation of aligned microchannels (yellow box) perpendicularly orientated in relation to the root within the periodontal compartment. (E) Regenerative outcome of the biphasic personalized scaffold demonstrating a high level of functional periodontal attachment (black arrows) into newly formed cementum (white arrows). Figure $2 \mathrm{~A}$ and $\mathrm{B}$ images reproduced from Park et al. (2010) and Figure 2C to E images reproduced from Park et al. (2012), with permission from publisher (Elsevier). This figure is available in color online at http://jdr.sagepub.com.

in nude mice, as shown in Figure 2B (Park et al., 2010). Notably, AdBMP-7-transfected gingival cells demonstrated bone and cementum formation on dentin surfaces, whereas nontransfected cells did not. This has implications for the translational potential of this approach, since there may be regulatory issues related to the use of adenovirus-transduced cells. Subsequently, biomimetic fiber-guiding scaffolds using similar 3-dimensional wax/solvent casting methods (Fig. 2C) were tested in an athymic rat periodontal defect model, which resulted in perpendicularly oriented microchannels (Fig. 2D) that provided guidance for periodontal fiber orientation at the root-ligament interface (Fig. 2E; Park et al., 2012). This time, AdBMP-7-transduced PDL cells were compared with nontransduced PDL cells, and the fiber-guiding scaffolds were able to promote new attachment formation with both cell types. Utilizing this technology, the authors advocated the manufacture of individualized multiphasic scaffolds via computational design and 3-dimensional printing (Park et al., 2013). This approach provides a template for future translational application of multiphasic scaffold approaches to periodontal tissue engineering.

\section{Compartmentalized Biphasic Scaffolds Combined with Cell Sheets}

A biphasic tissue-engineered construct made from PCL for the delivery of osteoblasts and PDL cells for periodontal regeneration has also been reported (Vaquette et al., 2012). The bone compartment was made with fused deposition modeling that had been utilized for bone regeneration, albeit for a different application (Probst et al., 2010). The periodontal compartment was composed of a solution electrospun membrane for the purpose of facilitating the delivery of PDL cell sheets (Fig. 3A and B). In this strategy, a key aim was to improve the stability and application of periodontal cell sheets onto the dentine root surface, as this was identified as a limitation of using cell sheets for periodontal regeneration (Iwata et al., 2009). This study showed that the periodontal compartment provides additional anchorage and support so that the adhesion and stability of the cell sheets is enhanced. This gain in tissue biomechanical stability decreases the risk of compromising the regeneration of the periodontal complex. In vitro, the bone compartment supported cell growth 

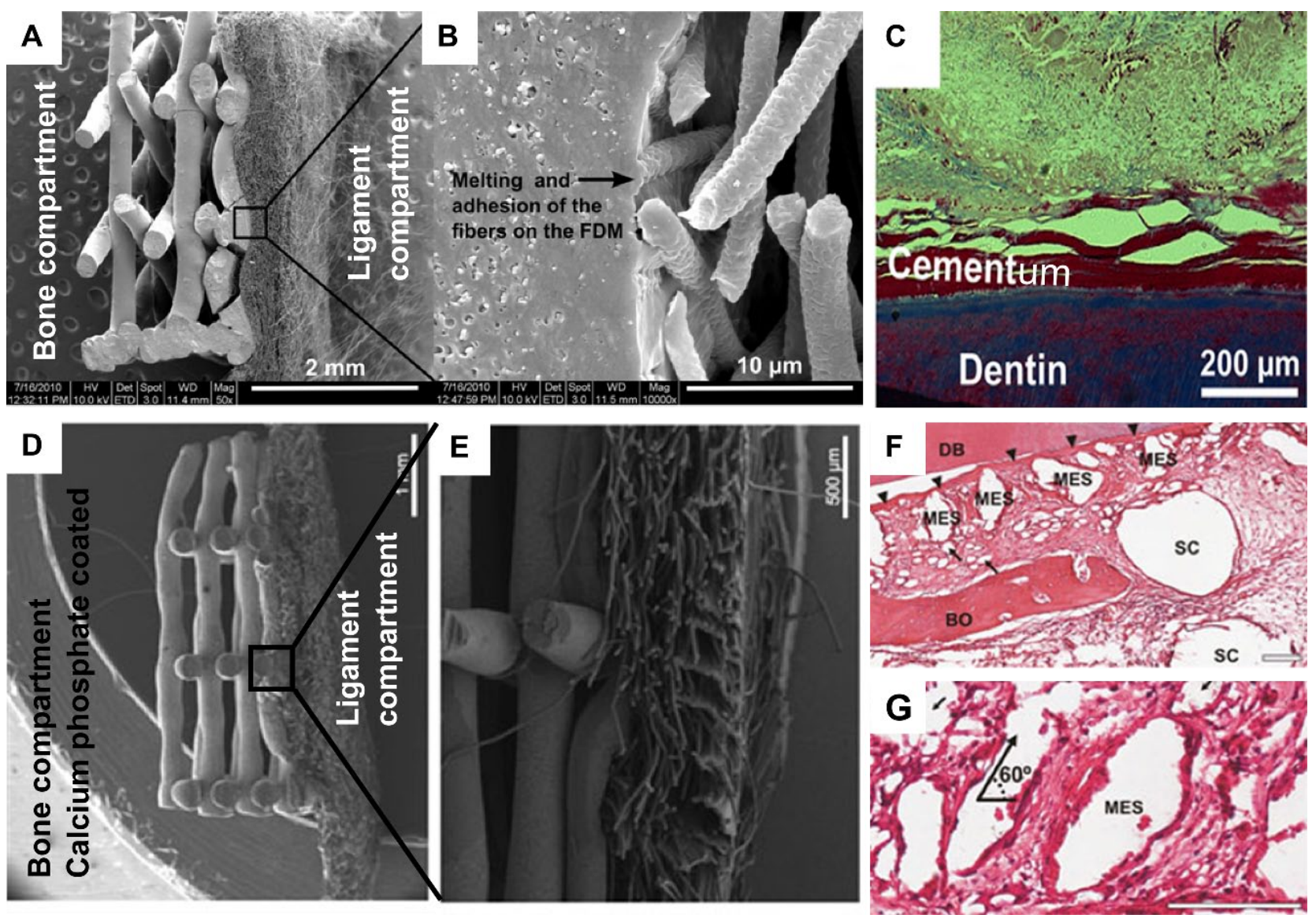

Figure 3. Compartmentalized biphasic scaffold utilized for delivering osteoblasts and periodontal fibroblast cell sheets. (A) Polycaprolactone scaffold composed of a fused deposition modeling scaffold and solution electrospun membrane for the bone and periodontal compartments, respectively. (B) Scanning electron micrograph demonstrating the excellent cohesion of both compartments. (C) Deposition of a mineralized tissue resembling cementum in an ectopic periodontal regeneration model in rats (Azan staining). (D) Biphasic scaffold surface modified by a layer of calcium phosphate material for improving the osteoconductive performance of the resulting construct. In this case, the periodontal compartment is composed of a macroscopic pore-size melt electrospun scaffold for emhancing the tissue integration between both compartments. (E) Crosssectional view of the biphasic scaffold. (F, G) Hematoxylin and eosin staining of regenerative outcome in an ectopic periodontal regeneration model in athymic rats. DB, dentin block; $\mathrm{BO}$, bone; SC, fused deposition modeling scaffold; MES, melt electrospun scaffold. Thin arrows indicate single-melt electrospun fibers. Triangular arrows indicate periodontal ligament. Scales are $100 \mu \mathrm{m}$. Figure $3 \mathrm{~A}$ to $\mathrm{C}$ images reproduced from Vaquette et al. (2012) and Figures D-G reproduced from Costa et al. (2014), with permission from the publishers (Elesvier and John Wiley and Sons, respectively).

and mineralization, and the periodontal component was suitable for supporting multiple PDL cell sheets. When applied onto a dentin block and implanted in a subcutaneous animal model, cementum deposition was seen on the surface of the dentin (Fig. 3C).

This concept was further developed by enhancing the osteoconductive nature of the bone compartment by coating the PCL with a layer of calcium phosphate (Fig. 3D; Costa et al., 2014). Furthermore, it was hypothesized that a periodontal compartment possessing a larger pore size could enhance the integration of the periodontal ligament with the newly formed alveolar bone. For this purpose, a melt electrospun membrane displaying a macroscopic pore size and possessing a high degree of flexibility and resilience (essential for supporting the cell sheet) was utilized for the periodontal compartment (Fig. 3D and E). The biphasic design combined with the cell sheet technology allowed culture of osteoblasts in the bone compartment and PDL sheet delivery on the membrane, prior to subcutaneous implantation of the compartmentalized tissues in an ectopic periodontal regeneration model in athymic rats. This study demonstrated excellent cross-communication between the bone and periodontal compartments, as shown in Figure 3F. The presence of the cell sheets led to the formation of a periodontal ligament-like tissue that was well integrated in the newly formed bone while enhancing the periodontal attachment onto dentin (Fig. 3F and $\mathrm{G})$. The potential of the melt electrospun membranes to facilitate periodontal regeneration has also been validated in a rat periodontal defect model, albeit with the use of a monophasic membrane (Dan et al., 2014).

A limitation of these approaches may be the stiffness of the bone compartment that was made via the fused deposition modeling method. Three-dimensional melt electrospun scaffolds have favorable porosity and a "sponge-like" consistency that 
would allow improved adaptability into periodontal defects, which clinically manifest in a variety of shapes and sizes. In support of this approach, tissue-engineered constructs made from 3-dimensional electrospun PCL scaffolds combined with osteoblasts were shown to promote bone formation in an ectopic rat model of bone formation (Vaquette $e t$ al., 2013).

\section{Compartmentalized Triphasic Scaffold}

In a further development, PCLhydroxylapatite scaffolds (90:10 wt $\%$ ) were fabricated with 3-dimensional printing (fused deposition modeling) in 3 phases (Lee et al., 2014): 100- $\mu \mathrm{m}$ microchannels in phase $\mathrm{A}$, designed for the cementum-dentin interface; $600-\mu \mathrm{m}$ microchannels in phase $\mathrm{B}$, designed for the PDL compartment; and $300-\mu \mathrm{m}$ microchannels in phase $\mathrm{C}$, designed for alveolar bone (Fig. 4A). Recombinant human amelogenin, connective tissue growth factor, and bone morphogenetic protein 2 were spatially delivered and time released in phases $\mathrm{A}, \mathrm{B}$, and $\mathrm{C}$, respectively. Initially, it was shown that after a 4-week in vitro incubation period, stem cells from different sourcesnamely, dental pulp stem/progenitor cells, PDL stem/progenitor cells, and alveolar bone stem/progenitor cellsformed distinct phenotypes. Collagen I-rich fibers were preferentially formed by the PDL stem/progenitor cells, while mineralized tissue was formed by dental pulp stem/progenitor cells, PDL stem/ progenitor cells, and alveolar bone stem/ progenitor cells. Upon in vivo implantation, dental pulp stem/progenitor cellseeded multiphasic scaffolds yielded aligned PDL-like collagen fibers that inserted into bone sialoprotein-positive bone-like tissue and putative cementum matrix protein 1-positive/dentin sialophosphoprotein-positive dentin/cementum tissues (Fig. 4B-D). The strategy used for the regeneration of multiphase periodontal tissues in this study involved the spatiotemporal delivery of multiple proteins. With this method, it was shown that a single stem/progenitor cell population appeared to differentiate into a putative cementum, PDL, and alveolar bone complex by using the scaffold's biophysical properties, combined with spatially released bioactive cues. One of the possible limitations of this approach may be the stiffness of the PCL scaffolds manufactured by the fused deposition modeling method, which may make it difficult to adopt the scaffold onto
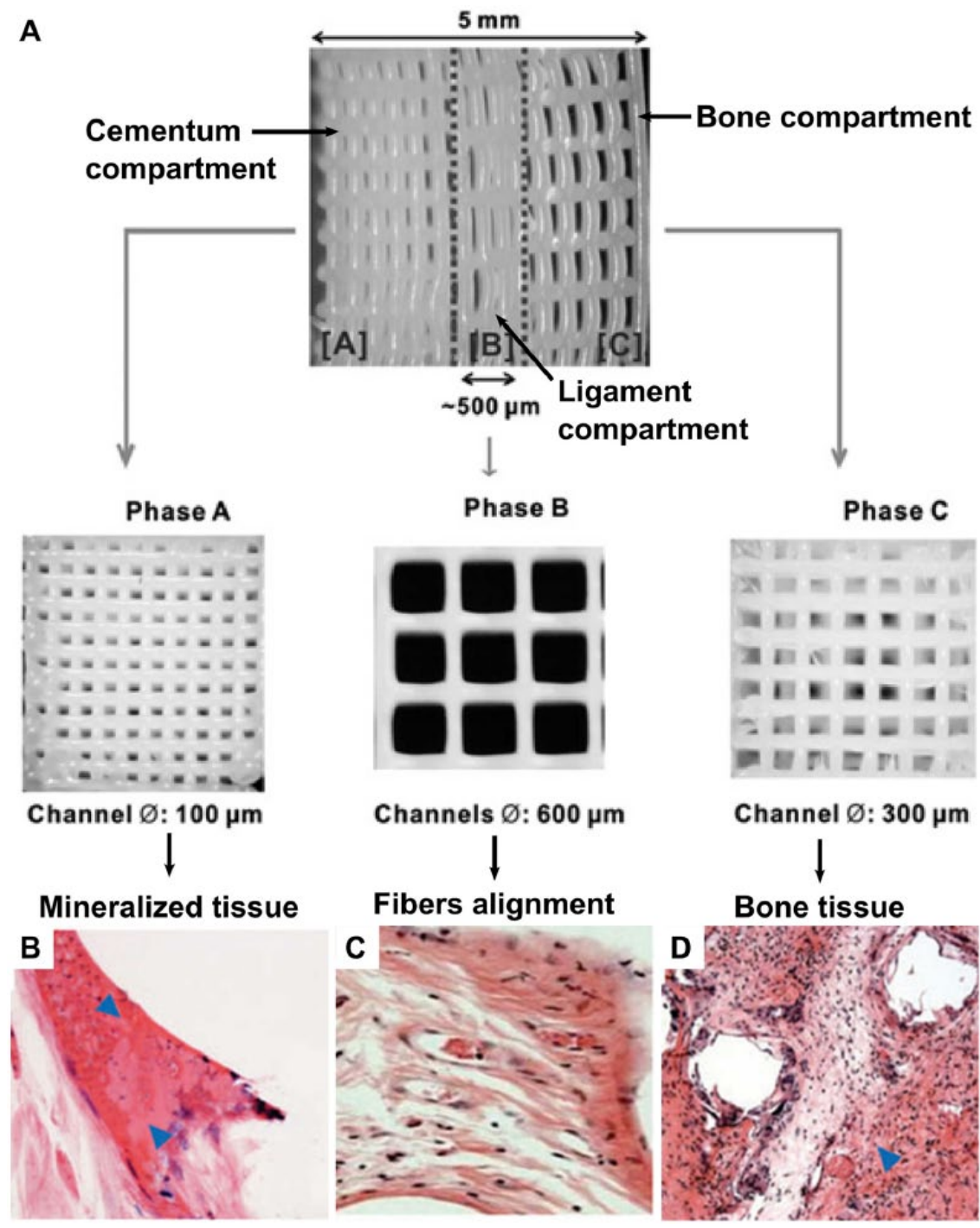

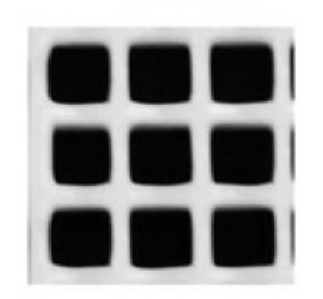

Channels $\varnothing: 600 \mu \mathrm{m}$

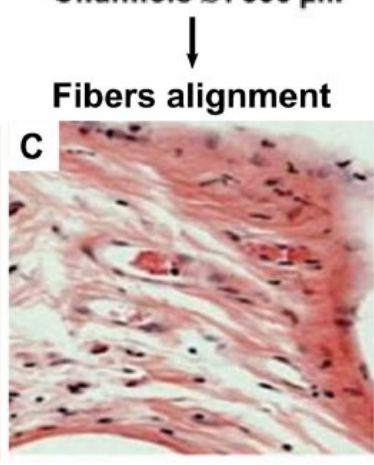

Phase C

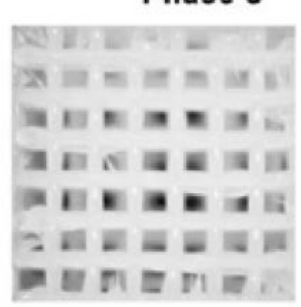

Channel $\varnothing: 300 \mu \mathrm{m}$ $\downarrow$

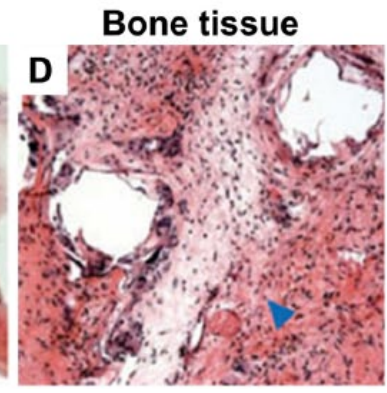

Figure 4. Compartmentalized triphasic scaffold. (A) Three-dimensional printed seamless scaffold with region-specific microstructure consisting of 3 phases: 100- $\mu \mathrm{m}$ microchannels with $2.5 \mathrm{~mm}$ in width (phase A, cementum compartment), 600- $\mu \mathrm{m}$ microchannels with $500 \mu \mathrm{m}$ in width (phase B, periodontal compartment), 300- $\mu \mathrm{m}$ microchannels with $2.25 \mathrm{~mm}$ in width (phase C, bone compartment). (B-D) Regenerative outcome of the cell-seeded scaffold in an ectopic murine model. Mineralized tissue (indicated by the arrows) was formed in the cementum and bone compartment, while collagenous fiber orientation was observed within the periodontal compartment. Images from Lee et al. (2014), reproduced with permission from the publisher (Mary Ann Liebert, Inc).

the root surface in clinical scenarios. Furthermore, it is unclear how the cementum component of the triphasic scaffold will be attached onto the root surface in a clinical scenario.

\section{SUMMARY AND CONCLUSION}

Multiphasic scaffolds-which allow compartmentalized tissue healing that is ultimately integrated into a cohesive structureare essential for controlling the necessary spatiotemporal events that would result in periodontal regeneration. Multiphasic scaffolds proposed for periodontal regeneration are largely characterized by the presence of bone and periodontal attachment compartments. The bone compartment often utilizes scaffold 
technology that has been shown to be successful elsewhere in the body. However, it is important that future approaches take into account the unique requirements for regenerating the bone compartment of periodontal defects - notably, the need for the scaffold to be of an appropriate stiffness and handling properties to adapt to clinical defects of varying size and shape. With regard to the periodontal ligament component, the focus must be on facilitating cementum formation onto the root surface and promoting perpendicular periodontal fiber formation and insertion into the newly formed cementum and bone. In the case of cementum formation, a key role of the scaffold would be the delivery and stabilization of appropriate cells at the tooth surface. Furthermore, the scaffold architecture can be utilized to guide the orientation of the regenerated periodontal fibers to facilitate perpendicular insertion into newly formed cementum. Preclinical in vitro and in vivo studies have made promising advances in multiphasic scaffold design, but these approaches need to be optimized and subsequently tested in large animal models and, ultimately, human clinical trials.

\section{ACKNOWLEDGMENTS}

The experimental work from the authors' laboratories that is included in this review is funded by the National Health and Medical Research Council of Australia. The authors declare no potential conflicts of interest with respect to the authorship and/ or publication of this article.

\section{REFERENCES}

Akizuki T, Oda S, Komaki M, Tsuchioka H, Kawakatsu N, Kikuchi A, et al. (2005). Application of periodontal ligament cell sheet for periodontal regeneration: a pilot study in beagle dogs. J Periodontal Res 40:245-251.

Bartold PM, McCulloch CA, Narayanan AS, Pitaru S (2000). Tissue engineering: a new paradigm for periodontal regeneration. Periodontol 2000 24:253-269.

Bartold PM, Xiao Y, Lyngstaadas SP, Paine ML, Snead ML (2006). Principles and applications of cell delivery systems for periodontal regeneration. Periodontol 2000 41:123-135.

Carlo-Reis EC, Borges AP, Araújo MV, Mendes VC, Guan L, Davies JE (2011). Periodontal regeneration using a bilayered PLGA/calcium phosphate construct. Biomaterials 32:9244-9253.

Caton J, Nyman S, Zander H (1980). Histometric evaluation of periodontal surgery: II. Connective tissue attachment levels after four regenerative procedures. J Clin Periodontol 7:224-231.

Chen J, Chen H, Li P, Diao H, Zhu S, Dong L, et al. (2011). Simultaneous regeneration of articular cartilage and subchondral bone in vivo using MSCs induced by a spatially controlled gene delivery system in bilayered integrated scaffolds. Biomaterials 32:4793-4805.

Costa PF, Vaquette C, Zhang Q, Reis RL, Ivanovski S, Hutmacher DW (2014). Advanced tissue engineering scaffold design for regeneration of the complex hierarchical periodontal structure. J Clin Periodontol 41:283-294.

Dan H, Vaquette C, Fisher A, Hamlet SM, Xiao Y, Hutmacher DW, et al. (2014). The influence of cellular source on periodontal regeneration using calcium phosphate coated polycaprolactone scaffold supported cell sheets. Biomaterials 35:113-122.

Darby IB, Morris KH (2013). A systematic review of the use of growth factors in human periodontal regeneration. J Periodontol 84:465-476.

Dormer NH, Berkland CJ, Detamore MS (2010). Emerging techniques in stratified designs and continuous gradients for tissue engineering of interfaces. Ann Biomed Eng 38:2121-2141.
Esposito M, Grusovin MG, Papanikolaou N, Coulthard P, Worthington HV (2009). Enamel matrix derivative (Emdogain(R)) for periodontal tissue regeneration in intrabony defects. Cochrane Database Syst Rev 4:CD003875.

Frenkel SR, Bradica G, Brekke JH, Goldman SM, Ieska K, Issack P, et al. (2005). Regeneration of articular cartilage-evaluation of osteochondral defect repair in the rabbit using multiphasic implants. Osteoarthritis Cartilage 13:798-807.

Gomez Flores M, Yashiro R, Washio K, Yamato M, Okano T, Ishikawa I (2008). Periodontal ligament cell sheet promotes periodontal regeneration in athymic rats. J Clin Periodontol 35:1066-1072.

Gottlow J, Nyman S, Lindhe J, Karring T, Wennström J (1986). New attachment formation in the human periodontium by guided tissue regeneration: case reports. J Clin Periodontol 13:604-616.

Harley BA, Lynn AK, Wissner-Gross Z, Bonfield W, Yannas IV, Gibson LJ (2010). Design of a multiphase osteochondral scaffold: III. Fabrication of layered scaffolds with continuous interfaces. J Biomed Mater Res A 92:1078-1093.

Hasegawa M, Yamato M, Kikuchi A, Okano T, Ishikawa I (2005). Human periodontal ligament cell sheets can regenerate periodontal ligament tissue in an athymic rat model. Tissue Eng 11:469-478.

Hirose M, Kwon OH, Yamato M, Kikuchi A, Okano T (2000). Creation of designed shape cell sheets that are non invasively harvested and moved onto another surface. Biomacromolecules 1:377-381.

Ho ST, Hutmacher DW, Ekaputra AK, Hitendra D, Hui JH (2010). The evaluation of a biphasic osteochondral implant coupled with an electrospun membrane in a large animal model. Tissue Eng Part A 16:11231141.

Hutmacher DW, Cool S (2007). Concepts of scaffold-based tissue engineering: the rationale to use solid free-form fabrication techniques. $J$ Cell Mol Med 11:654-669.

Hynes K, Menicanin D, Gronthos S, Bartold PM (2012). Clinical utility of stem cells for periodontal regeneration. Periodontol 2000 59:203-227.

Ishikawa I, Iwata T, Washio K, Okano T, Nagasawa T, Iwasaki $\mathrm{K}$, et al. (2009). Cell sheet engineering and other novel cell-based approaches to periodontal regeneration. Periodontol 2000 51:220-238.

Ivanovski S (2009). Periodontal regeneration. Aust Dent J 54(Suppl 1):118128.

Iwata T, Yamato M, Tsuchioka H, Takagi R, Mukobata S, Washio K, et al. (2009). Periodontal regeneration with multi-layered periodontal ligament-derived cell sheets in a canine model. Biomaterials 30:27162723.

Jeon JE, Vaquette C, Theodoropoulos C, Klein TJ, Hutmacher DW (2014). Multiphasic construct studied in an ectopic osteochondral defect model. $J R$ Soc Interface 11:20140184.

Karring T, Nyman S, Gottlow J, Laurell L (1993). Development of the biological concept of guided tissue regeneration: animal and human studies. Periodontol 2000 1:26-35.

Kon E, Delcogliano M, Filardo G, Fini M, Giavaresi G, Francioli S, et al. (2010). Orderly osteochondral regeneration in a sheep model using a novel nano-composite multilayered biomaterial. J Orthop Res 28:116124.

Kushida A, Yamato M, Konno C, Kikuchi A, Sakurai Y, Okano T (1999). Decrease in culture temperature releases monolayer endothelial cell sheets together with deposited fibronectin matrix from temperatureresponsive culture surfaces. J Biomed Mater Res 45:355-362.

Lam CX, Hutmacher DW, Schantz JT, Woodruff MA, Teoh SH (2009). Evaluation of polycaprolactone scaffold degradation for 6 months in vitro and in vivo. J Biomed Mater Res A 90:906-919.

Lee CH, Hajibandeh J, Suzuki T, Fan A, Shang P, Mao JJ (2014). Threedimensional printed multiphase scaffolds for regeneration of periodontium complex. Tissue Eng Part A 20:1342-1351.

Lu HH, Subramony SD, Boushell MK, Zhang X (2010). Tissue engineering strategies for the regeneration of orthopedic interfaces. Ann Biomed Eng 38:2142-2154.

Mrosek EH, Schagemann JC, Chung HW, Fitzsimmons JS, Yaszemski MJ, Mardones RM, et al. (2010). Porous tantalum and poly-epsilon- 
caprolactone biocomposites for osteochondral defect repair: preliminary studies in rabbits. $J$ Orthop Res 28:141-148.

Murakami S (2011). Periodontal tissue regeneration by signaling molecule(s): what role does basic fibroblast growth factor (FGF-2) have in periodontal therapy? Periodontol 2000 56:188-208.

Needleman IG, Worthington HV, Giedrys-Leeper E, Tucker RJ (2006). Guided tissue regeneration for periodontal infra-bony defects. Cochrane Database Syst Rev 2:CD001724.

Park CH, Rios HF, Jin Q, Bland ME, Flanagan CL, Hollister SJ, et al. (2010). Biomimetic hybrid scaffolds for engineering human toothligament interfaces. Biomaterials 31:5945-5952.

Park CH, Rios HF, Jin Q, Sugai JV, Padial-Molina M, Taut AD, et al. (2012). Tissue engineering bone-ligament complexes using fiber-guiding scaffolds. Biomaterials 33:137-145.

Park CH, Rios HF, Taut AD, Padial-Molina M, Flanagan CL, Pilipchuk SP, et al. (2013). Image-based, fiber guiding scaffolds: A platform for regenerating tissue interfaces. Tissue Eng Part C Methods 20:533-542.

Probst FA, Hutmacher DW, Müller DF, Machens HG, Schantz JT (2010). Calvarial reconstruction by customized bioactive implant. Handchir Mikrochir Plast Chir 42:369-373.
Requicha JF, Viegas CA, Muñoz F, Azevedo JM, Leonor IB, Reis RL, et al. (2014). A tissue engineering approach for periodontal regeneration based on a biodegradable double-layer scaffold and adipose-derived stem cells. Tissue Eng Part A. [Epub ahead of print 4/22/2014]

Scotti C, Buragas MS, Mangiavini L, Sosio C, Di Giancamillo A, Domeneghini C, et al. (2007). A tissue engineered osteochondral plug: an in vitro morphological evaluation. Knee Surg Sports Traumatol Arthrosc 15:1363-1369.

Vaquette C, Cooper-White J (2013). A simple method for fabricating 3-D multilayered composite scaffolds. Acta Biomater 9:4599-1608.

Vaquette C, Fan W, Xiao Y, Hamlet S, Hutmacher DW, Ivanovski S (2012). A biphasic scaffold design combined with cell sheet technology for simultaneous regeneration of alveolar bone/periodontal ligament complex. Biomaterials 33: 5560-5573.

Vaquette C, Ivanovski S, Hamlet SM, Hutmacher DW (2013). Effect of culture conditions and calcium phosphate coating on ectopic bone formation. Biomaterials 34:5538-5551.

Wang W, Li B, Yang J, Xin L, Li Y, Yin H, et al. (2010). The restoration of full-thickness cartilage defects with BMSCs and TGF-beta 1 loaded PLGA/fibrin gel constructs. Biomaterials 31:8964-8973. 